\title{
Evidence-Based Medicine (EBM) in Practice: Understanding Tests of Heterogeneity in Metaanalysis
}

\author{
Philip S. Schoenfeld, M.D., M.S.Ed., M.Sc. (Epi), ${ }^{1}$ and Edward V. Loftus, Jr., M.D. ${ }^{2}$ \\ ${ }^{1}$ Division of Gastroenterology, University of Michigan School of Medicine and Veterans Affairs Center for \\ Excellence in Health Services Research, Ann Arbor, Michigan; and ${ }^{2}$ Division of Gastroenterology, Mayo Clinic, \\ Rochester, Minnesota
}

\section{CLINICAL QUESTIONS}

How effective is azathioprine at preventing recurrent flares of Crohn's disease among patients with quiescent disease? When should a patient with Crohn's disease start azathioprine?

\section{CASE SCENARIO}

An 18-yr-old woman presents with right lower quadrant abdominal discomfort, unintentional 5-pound weight loss, and intermittent diarrhea for the past 3 months. Initial evaluation reveals mild normocytic anemia, elevated ESR, and stool cultures with normal flora. Small bowel follow through demonstrates a stricture of the distal $15 \mathrm{~cm}$ of the ileum. Colonoscopy reveals inflammation in the terminal ileum and biopsies are consistent with Crohn's disease. The patient is started on prednisone $40 \mathrm{mg}$ daily and the dose is tapered over 8 wk. Her symptoms resolve within 2 wk of starting prednisone.

Recently, you read an article (1) which stated that the use of immunosuppressant agents has increased in patients with Crohn's disease over the past $25 \mathrm{yr}$, and approximately 56\% of these patients used immunosuppressant agents in 19982003 in Europe. During that period of 25 yr, intestinal resection for medical failure decreased, but intestinal resection for stricturing and perforating complications did not change. Approximately $50 \%$ of patients who underwent surgery never received immunosuppressants and 30\% did not receive immunosuppressant agents for more than $12 \mathrm{wk}$. Therefore, the authors hypothesized that under-utilization of immunosuppressant agents prevented a reduction in intestinal surgery for intestinal complications.

You wonder if azathioprine should be started in your patient.

\section{EBM APPROACH}

A metaanalysis of six randomized controlled trials (RCT) $(\mathrm{n}=319$ total patients) compared azathioprine versus placebo for prevention of recurrent flares in patients with quiescent Crohn's disease (2). Five of the six RCTs did not produce a statistically significant result. In the metaanalysis, patients using azathioprine were much more likely to stay in remission compared to patients using placebo: $\mathrm{OR}=2.27$ (95\% CI: 1.76-2.93). Overall, 67\% (95\% CI: 59-75\%) of azathioprinetreated patients remained in remission versus 53\% (95\% CI: $45-60 \%)$ of placebo-treated patients.

\section{TERMINOLOGY}

A systematic review is a review that utilizes explicit techniques to systematically search, critically appraise, and synthesize published studies that address a specific question. A metaanalysis is a quantitative systematic review where statistical techniques are used to combine the results from individual studies. Thus, proper performance of a metaanalysis requires development of an appropriate question that identifies specific patients, specific interventions, and a specific outcome (e.g., among patients with quiescent Crohn's disease, is azathioprine more effective than placebo at maintaining remission of Crohn's disease). A comprehensive literature search must be performed to identify all published studies that address this question. Also, metaanalyses of treatments usually limit the literature search to randomized trials, since this design produces more accurate results as confounding factors are reduced or removed (3). If these trials are also "doubleblind", then bias is also eliminated (3). A detailed discussion of appropriate metaanalysis design may be found in other texts (4).

Metaanalysis is most helpful when multiple small RCTs suggest that a treatment is better than placebo, but most RCTs do not produce statistically significant results. In this situation, the treatment may be better than placebo, but a significant result could not be demonstrated because of an insufficient sample size (i.e., an insufficient number of enrolled patients). This is sometimes called a Type II error (3). In a metaanalysis, the results from all RCTs are combined to produce a summary result using a statistical technique. By combining the results from all RCTs, a large number of patients are examined and a sufficient sample size is achieved.

This may seem like "magic"! How can you put the data from multiple RCTs into a "black box," which spits out a 
Favors placebo

Favors azathioprine

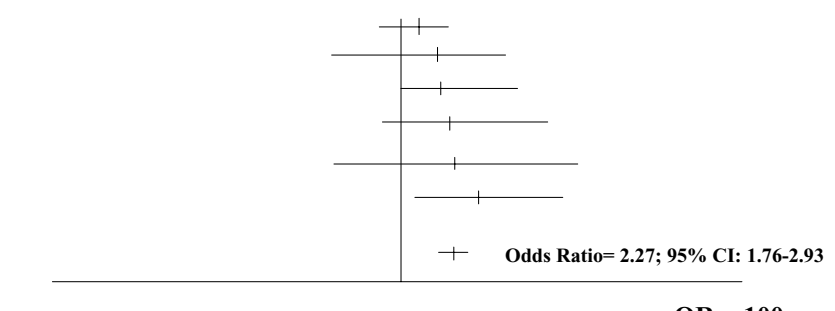

$\mathbf{O R}=\mathbf{0 . 0 1}$

$\mathrm{OR}=\mathbf{1 . 0}$

$\mathrm{OR}=\mathbf{1 0 0}$

Test of Heterogeneity: $p=0.12$

Figure 1. Azathioprine versus Placebo for quiescent Crohn's disease.

summary result? For a valid metaanalysis, we rely on an important principle: if multiple RCTs examined the same types of patients (patients with quiescent Crohn's disease) with a similar intervention (azathioprine vs placebo) and examined a similar outcome (maintenance of remission of Crohn's disease) and used a similar study design (RCT), then differences between individual study results only occurred due to chance and it is valid to combine the results from individual studies into a metaanalysis. Figure 1 displays a Petogram, which is the standard diagram for representing metaanalysis results. There are six studies represented in this Petogram. For each study, the vertical line represents the study result (expressed as an odds ratio or OR) and the horizontal line represents the $95 \%$ confidence intervals $(95 \% \mathrm{CI})$. As you can see, five of the six studies did not produce statistically significant results: the horizontal lines $(95 \% \mathrm{CI})$ from these studies cross the center of the Petogram $(\mathrm{OR}=1.0)$, which indicates a nonstatistically significant result. At the bottom of Figure 1, the summary result of the metaanalysis is provided: $\mathrm{OR}=$ 2.27; 95\% CI: 1.76-2.93. Since a large number of patients $(\mathrm{n}=319)$ are included in the metaanalysis, a precise and statistically significant estimate of the beneficial effects of azathioprine is produced.

However, can we be sure that the individual studies used similar patients, similar interventions, and measured similar

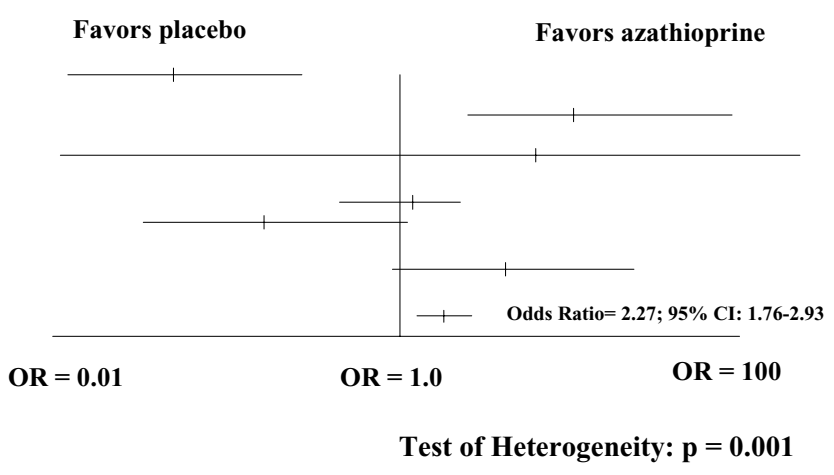

Figure 2. Hypothetical results for a metaanalysis with a highly significant test of heterogeneity. study outcomes? If the individual studies produced similar results, then this principle is probably fulfilled. We assess this issue with the test of heterogeneity, which determines if the differences between individual study results could have occurred due to chance or if the differences between individual study results are quite different and could not have occurred due to chance. If there are statistically significant differences between the results of individual studies, then the test of heterogeneity provides $p<0.10$. In this situation, we assume that the differences in results between individual studies occurred because of important differences in study design, patient population, measurement of outcomes, etc. This concept is demonstrated in Figure 2, which is a hypothetical example of a metaanalysis that uses the widely divergent results from multiple RCTs. Although this hypothetical metaanalysis produces a statistically significant summary result $(\mathrm{OR}=2.27$ with 95\% CI: 1.76-2.93), this is not a valid metaanalysis because the test of heterogeneity provides a $p$-value $=0.001$, indicating that these studies are too different in study design to combine into a metaanalysis.

If there are not statistically significant differences between study results, then we assume that differences in individual study results occurred due to chance and not because of important differences in study design. In this situation, the test of heterogeneity produces a $p$-value $>0.10$ (Figure 1).

\section{APPLICATION OF METAANALYSIS RESULTS AND TEST OF HETEROGENEITY TO THE CLINICAL QUESTION}

In the metaanalysis, patients with quiescent Crohn's disease were more likely to remain in remission compared to patients receiving placebo: $\mathrm{OR}=2.27 ; 95 \% \mathrm{CI}: 1.76-2.93$. The test of heterogeneity $=0.12$, indicating that there are not significant differences between the results of individual studies and that the differences in results of individual studies probably occurred due to chance. Overall, 67\% (95\% CI: 59-75\%) of azathioprine-treated patients remained in remission versus 53\% (95\% CI: 45-60\%) of placebo-treated patients.

\section{APPLYING RESULTS TO YOUR PATIENT}

In the metaanalysis by Pearson et al. (2), two of the RCTs enrolled steroid-dependent Crohn's disease patients, one trial enrolled patients who had achieved remission on azathioprine, and three trials enrolled patients who were in remission and had completed steroid tapers. Therefore, at least some of the patients in this metaanalysis resemble your patient. However, approximately $9 \%$ of Crohn's disease patients experienced adverse events with use of immunosuppressive agents significant enough to result in withdrawal from the study (2). These adverse events included leukopenia, anemia, and pancreatitis (2). Patients using azathioprine get periodic checks of their complete blood cell count and liver enzymes. Also, there is a small but real risk of congenital anomalies among 
offspring of patients using azathioprine or 6-mercaptopurine (5).

\section{BOTTOM LINE}

In practice, we would definitely start this patient on azathioprine if she suffers a second flare of Crohn's disease in the next 12 months. Many of our colleagues would even start azathioprine after the first course of prednisone or even during the initial prednisone tapering period since azathioprine has also been shown to be effective at inducing remission in active Crohn's disease (2). Furthermore, an 18month randomized trial of 6-mercaptopurine versus placebo in newly diagnosed pediatric patients with Crohn's disease on corticosteroids showed that mercaptopurine not only lowered the duration and cumulative dose of corticosteroids required to induce remission, it also lowered the risk of relapse after steroid-induced remission (6). Overall, we do think that azathioprine is under-utilized in patients with Crohn's disease due to safety concerns. Although these safety concerns are real, the benefits of azathioprine outweigh the risks in the majority of patients with Crohn's disease. Although 5aminosalicylate agents are quite safe, we do not believe that they are an effective alternative for maintenance of medically induced remission of ileocecal Crohn's disease, and this is borne out by a recently published Cochrane metaanalysis (7).
Reprint requests and correspondence: Philip Schoenfeld, M.D., VACM III-D, 2215 Fuller Road, Ann Arbor, MI 48105.

Received March 22, 2005; accepted March 22, 2005.

\section{REFERENCES}

1. Cosnes J, Nion-Larmurier I, Beaugerie L, et al. Impact of the increasing use of immunosuppressants in Crohn's disease on the need for intestinal surgery. Gut 2005;54:23741.

2. Pearson DC, May GR, Fick GH, et al. Azathioprine and 6mercaptopurine in Crohn's disease: A meta-analysis. Ann Intern Med 1995;122:132-42.

3. Schoenfeld P, Cook D, Hamilton S, et al. An evidencebased approach to gastroenterology therapy. Gastroenterology 1999; 116:1230-37.

4. Oxman AD, Cook DJ, Guyatt G. for the Evidence Based Medicine Working Group. Users' guide to the medical literature. VI. How to use an overview. JAMA 1994;272:1367-71.

5. Norgard B, Pedersen L, Fonanger K, et al. Azathioprine, mercaptopurine and birth outcome: A population-based study. Aliment Pharmacol Ther 2003;17:827-34.

6. Markowitz J, Grancher K, Kohn N, et al. for the Pediatric 6MP Collaborative Group. A multicenter trial of 6-mercaptopurine and prednisone in children with newly diagnosed Crohn's disease. Gastroenterology 2000;119:895902 .

7. Akobeng AK, Gardener E. Cochrane Inflammatory Bowel Disease Group. Oral 5-aminosalicylic acid for maintenance of medically-induced remission in Crohn's disease. Cochrane Database Syst Rev 2005, 1. 